\title{
QUANTIFICAÇÃO DO ESTOQUE DE CARBONO E AVALIAÇÃO ECONÔMICA DE DIFERENTES ALTERNATIVAS DE MANEJO EM UM PLANTIO DE EUCALIPTO ${ }^{1}$
}

\author{
Fausto Araújo Paixão², Carlos Pedro Boechat Soares³, Laércio Antônio Gonçalves Jacovine³ ${ }^{3}$ Márcio
} Lopes da Silva ${ }^{3}$, Helio Garcia Leite ${ }^{3}$ e Gilson Fernandes da Silva ${ }^{4}$

\begin{abstract}
RESUMO - Este estudo teve por objetivos: quantificar o estoque de madeira para a produção de carvão e serraria em uma floresta de eucalipto; quantificar o estoque de carbono nos diferentes compartimentos da floresta; e avaliar economicamente alternativas de manejo, com vista à inserção de povoamentos florestais no mecanismo de desenvolvimento limpo e na venda de créditos de carbono. Para isso, realizou-se um inventário florestal em uma plantação de Eucalyptus grandis, com 6 anos de idade, no Município de Viçosa, Minas Gerais. Após as análises, verificou-se que: a) o fuste é o componente da árvore que mais contribui, em média, para o total de carbono da parte aérea $(81,84 \%)$, seguido por casca $(8,05 \%)$, galhos $(7,74 \%)$ e folhas $(2,57 \%)$; b) 47,7 toneladas de carbono por hectare estão estocadas na parte aérea das árvores; 14,71 nas raízes e 8,72 na manta orgânica, totalizando 71,13 toneladas de carbono por hectare; c) a produção de madeira somente para a venda de créditos de carbono, sem considerar o seu uso final, é economicamente viável, segundo critérios quantitativos de avaliação do projeto, se a tonelada de carbono for comercializada a preços maiores que US\$ 10,07; e d) a venda de créditos de carbono torna o empreendimento ainda mais atrativo economicamente, sobretudo porque a receita é auferida no início do projeto.
\end{abstract}

Palavras-chave: Seqüestro de carbono, uso múltiplo e eucalipto.

\section{QUANTIFICATION OF CARBON STOCK AND ECONOMIC EVALUATION OF MANAGEMENT ALTERNATIVES IN A EUCALYPT PLANTATION}

\begin{abstract}
The objectives of this study were: to quantify the wood stock for coal production and for sawmill in an eucalypt stand;) to quantify the carbon stock in the various compartments of the forest; and to evaluate economically management alternatives in order to include forest stands in the Clean Development Mechanism and in the sale of the carbon credits. In order to do so, a forest inventory in a 6-year-old plantation of Eucalyptus grandis, located in Viçosa, Minas Gerais State, Brazil, was carried out. The analysis showed that: a) the stem is a tree component that contributes the most, in average, for total carbon of the aerial part (81.84\%), followed by the bark ( $8.05 \%)$, branches (7.74\%), and leaves (2.57\%); b) 47.7 tons of the carbon per hectare are stocked in the aerial parts of the trees; 14.71 tons in the roots; and 8.72 tons in the organic litter; totaling 71.13 tons of carbon per hectare; c) the wood production for the sale of carbon credits only, without considering its final use, is economically feasible, according to quantitative criteria of the project evaluation, if the ton of carbon was commercialized at prices higher than US\$10.07; d) the sale of the carbon credits makes the activity even more attractive economically, mainly because the income enters at the beginning of the project.
\end{abstract}

Keywords: Carbon sequestration, multiple use and eucalypt.

\footnotetext{
${ }^{1}$ Recebido em 09.11.2004 e aceito para publicação em 05.04.2006.

${ }^{2}$ Duratex S.A., Caixa Postal 50, 17120-000 Agudos-SP.

${ }^{3}$ Departamento de Engenharia Florestal da UFV. E-mail: <csoares@ ufv.br>.

${ }^{4}$ Departamento de Engenharia Florestal da UFES. NEDTEC - Jerônimo Monteiro. 29550-000 Alegre-ES.
} 


\section{INTRODUÇÃO}

Desde o início das discussões sobre as mudanças climáticas, em diferentes fóruns mundiais, o uso da terra e das florestas como mecanismo para mitigar as mudanças climáticas devido ao efeito-estufa sempre foi considerado. No entanto, por causa de incertezas científicas sobre as emissões de $\mathrm{CO}_{2}$ decorrentes das atividades de desmatamento e sobre as taxas de desmatamento em todo o mundo, esse assunto gera, ainda, muita polêmica. Somente a partir do estabelecimento dos mecanismos de flexibilização no Protocolo de Quioto, em 1997, na Convenção das Partes3 (COP-3), o foco da discussão migrou para o seqüestro de carbono pelas florestas, como uma das alternativas de compensação das emissões dos países industrializados (YU, 2002).

Tendo em vista esse foco, o Brasil poderá assumir uma posição privilegiada em relação aos países que buscam reverter o processo de mudança climática global, tanto do ponto de vista das reduções de emissões (evitando queimadas) quanto do seqüestro de carbono (através de reflorestamentos), uma vez que poucos países possuem condições climáticas e tecnológicas apropriadas para a produção florestal como o Brasil (ROCHA, 2002).

Diante da possibilidade da utilização das florestas como mitigador de problemas ambientais (climáticos), há necessidade de utilização de um manejo florestal moderno, que requeira a integração entre floresta, indústria e mercado, a fim de maximizar o retorno financeiro e, ao mesmo tempo, garantir uma base sustentável do estoque de crescimento das florestas. Para isso, é importante que sejam desenvolvidas e utilizadas técnicas que visem identificar as oportunidades, as alternativas de uso e as estimativas de diferentes produtos que as florestas podem oferecer (LEITE, 1994).

Em um mercado globalizado e cada vez mais competitivo, a possibilidade de agregar valores às florestas plantadas, com o emergente "mercado de créditos de carbono", e de contribuir para redução nas emissões de $\mathrm{CO}_{2}$ na atmosfera cria perspectivas otimistas de expansão para o setor florestal brasileiro. Embora o setor florestal possa se beneficiar, existem poucos trabalhos evidenciando o potencial real das florestas nesse mercado. Inúmeras estimativas têm sido feitas baseando-se em estimativas volumétricas dos fustes das árvores, as quais são convertidas em biomassa e em carbono. Trabalhos incluindo estimativas precisas dos diversos compartimentos da floresta (solo, raízes, copa das árvores, manta orgânica etc.) ainda são escassos, porém começam a ser executados (SCHUMACHER et al., 2002; WALTZLAWICK et al., 2002; REZENDE, 2002; CALDEIRA et al., 2002).

Diante dessa constatação, observa-se a necessidade de projetos na área de mensuração e manejo florestal, relacionados ao desenvolvimento de técnicas e métodos para a estimação do estoque de carbono em árvores individuais e nos diversos componentes da floresta, bem como de estudos de viabilidade econômica, incluindo o seqüestro de carbono. Os resultados de estudos dessa natureza são de extrema importância para os projetos que objetivam o atendimento do Mecanismo de Desenvolvimento Limpo (MDL), pois irão subsidiar o monitoramento de planos de manejo florestal voltado ao seqüestro de carbono; definir as linhas gerais de projetos de recuperação florestal de áreas degradadas; e definir alternativas de manejo florestal, entre outros.

Nesse sentido, o presente estudo foi desenvolvido objetivando quantificar o estoque de madeira para carvão e serraria em uma floresta de eucalipto; quantificar o estoque de carbono nos diferentes compartimentos da floresta; e avaliar economicamente diferentes alternativas de manejo, considerando-se o uso da madeira para carvão e serraria e o potencial para geração de créditos de carbono presente na floresta.

\section{MATERIAL E MÉTODOS}

O presente estudo foi realizado em um povoamento de Eucalyptus grandis W. Hill ex Maiden com 5,0 ha de área, 72 meses de idade, espaçamento inicial de plantio igual a 3 x 2 m, localizado no Município de Viçosa, Minas Gerais (latitude $20^{\circ} 45^{\prime}$ S, longitude W. Gr 42 $52^{\prime}$ e altitude média de 649 metros).

Foram lançadas oito parcelas de $400 \mathrm{~m}^{2}(20 \mathrm{~m} \mathrm{x}$ $20 \mathrm{~m}$ ), considerando-se dois estratos, nas quais foram medidos os diâmetros com casca a 1,3 m do solo (dap) de todas as árvores com diâmetros iguais ou superiores que $5,0 \mathrm{~cm}$ e a altura total $(H t)$ das 10 primeiras árvores. As alturas das demais árvores foram obtidas através de uma equação hipsométrica referente ao seguinte modelo:

$$
L n H t=\beta_{0}+\beta_{1}\left(\frac{1}{d a p}\right)+\varepsilon
$$


em que:

$d a p=$ diâmetro com casca a 1,30 $\mathrm{m}$ de altura, em cm;

$H t=$ altura total, em $\mathrm{m}$;

$\mathrm{Ln}=\log$ aritmo neperiano;

$\beta_{0}$ e $\beta_{1}=$ parâmetros do modelo; e

$\varepsilon=$ erro aleatório.

Os volumes das árvores individuais, para diferentes usos, ou seja, até diferentes diâmetros-limite de utilização, foram obtidos através da equação referente ao modelo de Kozak et al. (1969), assim representado:

$$
\left(\frac{d}{d a p}\right)^{2}=\beta_{0}+\beta_{1} \times\left(\frac{h}{H t}\right)+\beta_{2} \times\left(\frac{h}{H t}\right)^{2}+\varepsilon
$$

em que:

$d=$ diâmetro-limite de utilização, em cm;

$h=$ altura em que ocorre determinado diâmetro (d), em m;

$\beta_{0}, \beta_{1} \mathrm{e} \beta_{2}=$ parâmetros do modelo; e

$\varepsilon=$ erro aleatório.

A expressão para a obtenção do volume com casca e sem casca até um diâmetro $d$ qualquer do modelo de Kozak et al. (1969) é assim definida:

$$
\hat{V}=\frac{\pi}{40000} \times \operatorname{dap}^{2}\left[\hat{\beta}_{0} \times\left(h_{2}-h_{1}\right)+\hat{\beta}_{1} \times\left(\frac{h_{2}^{2}-h_{1}^{2}}{2 H t}\right)+\hat{\beta}_{2} \times\left(\frac{h_{2}^{3}-h_{1}^{3}}{3 H t^{2}}\right)\right]
$$

em que:

$h_{l}=$ altura mínima a ser considerada. Nesse caso, $h_{l}=0$ (nível do solo); e

$h_{2}=$ altura em que ocorre determinado diâmetro $d$.

Os diâmetros-limite de utilização $(d)$ e os respectivos usos da madeira, neste estudo, estão representados no Quadro 1.

A equação de taper, ou afilamento, foi ajustada utilizando-se dados obtidos por Soares e Paula Neto (1997), em um procedimento de cubagem rigorosa de árvores de Eucalyptus grandis, em um povoamento florestal localizado próximo à área de estudo e de idade aproximada.
Quadro 1 - Diâmetros-limite (d) de utilização para carvão e serraria

Table 1 -Diameter limit (d) for coal and sawmill

\begin{tabular}{cc}
\hline Uso & $\mathrm{d}_{\mathrm{cc}}(\mathrm{cm})$ \\
\hline Carvão & 3 \\
Serraria & 15 \\
\hline
\end{tabular}

$\mathrm{cc}=\mathrm{com}$ casca

Os critérios adotados para avaliação do ajuste da equação hipsométrica e da equação de taper foram: coeficiente de determinação $\left(R^{2}\right)$, coeficiente de variação e análise gráfica dos resíduos porcentuais.

As estimativas de carbono presentes no conjunto de folhas e galhos e no fuste de cada árvore foram obtidas pelas seguintes equações (SOARES e OLIVEIRA, 2002):

- Fuste (sem casca):

$$
\begin{gathered}
\operatorname{Ln}(\mathrm{Y})=-6,966833+1,587810 \times \operatorname{Ln}(\text { dap })+2,000404 \\
\quad \mathrm{x} \operatorname{Ln}(H t) \\
\mathrm{R}^{2}=98,82 \% \\
\mathrm{CV}=16,30 \%
\end{gathered}
$$

- Fuste (com casca):

$$
\begin{gathered}
\operatorname{Ln}(\mathrm{Y})=-6,609865+1,661056 \times \operatorname{Ln}(\text { dap })+1,851121 \\
\quad \mathrm{~L} \operatorname{Ln}(H t) \\
\mathrm{R}^{2}=98,90 \% \quad \mathrm{CV}=14,98 \%
\end{gathered}
$$

- Galhos:

$$
\begin{aligned}
\operatorname{Ln}(\mathrm{Y})= & -1,695267+3,888792 \times \operatorname{Ln}(\text { dap })-2,492777 \\
& \mathrm{x} \operatorname{Ln}(H t)
\end{aligned}
$$

$$
\mathrm{R}^{2}=88,27 \% \quad \mathrm{CV}=39,37 \%
$$

\section{- Folhas :}
$\operatorname{Ln}(\mathrm{Y})=-6,649474+2,273838 \times \operatorname{Ln}($ dap $)-0,1555153$ $\mathrm{x} \operatorname{Ln}(H t)$

$$
\mathrm{R}^{2}=85,40 \% \quad \mathrm{CV}=57,33 \%
$$

De posse da equação de afilamento e das equações de carbono para as diferentes partes das árvores, as oito parcelas do inventário foram totalizadas, obtendose as estimativas médias dos volumes por hectare (carvão e serraria), bem como a estimativa média por hectare do estoque de carbono somente armazenado na parte aérea das árvores (fuste, galhos e folhas).

Considerando que esse estoque de carbono da parte aérea representa $67,06 \%$ do carbono total armazenado em uma floresta de eucalipto com 6 anos

R. Árvore, Viçosa-MG, v.30, n.3, p.411-420, 2006 
de idade (PAIXÃO, 2004), a estimativa média do carbono total por hectare, incluindo, além da parte aérea, o sistema radicular e a manta orgânica, foi obtida pela seguinte expressão:

$$
\text { CTotal }=\text { CParteaérea } \times \frac{100}{67,06}
$$

Ainda de acordo com Paixão (2004), a manta orgânica (CMO) e o sistema radicular (CSR) contribuem, em média, com 12,26 e 20,68\% do carbono total, respectivamente. Assim, as estimativas médias do carbono por hectare armazenado nesses compartimentos puderam ser obtidas através das seguintes expressões:

$$
\begin{aligned}
& C M O=C \text { Total } \times 0,1226 \\
& C S R=C \text { Total } \times 0,2068
\end{aligned}
$$

Com as estimativas médias dos volumes por hectare para diferentes usos e da estimativa média do carbono total estocado por hectare, procedeu-se à analise econômica das seguintes alternativas de manejo mostradas no Quadro 2.

A inclusão do carbono total nas alternativas 4 e 5 teve como objetivo verificar a agregação de valor do carbono estocado, considerando-o como um produto alternativo da atividade florestal tradicional.

Para a análise econômica, consideraram-se as seguintes atividades e os seguintes custos por hectare (Quadro 3), referentes a um projeto de reflorestamento definido como de baixa tecnologia e com reduzido uso de máquinas, equipamentos e insumos.

O horizonte de planejamento foi igual à idade do povoamento (6 anos); os preços da madeira em pé (CEPEA, 2003) e do carbono estocado são apresentados no Quadro 4.

As receitas por hectare, referentes à venda de madeira, foram obtidas multiplicando-se os respectivos preços pelos volumes médios por hectare. A receita auferida pelos créditos de carbono foi obtida, multiplicando-se a estimativa média do total estocado pelo respectivo preço por tonelada.

Quadro 2 - Alternativas de manejo Table 2 - Management alternatives

\begin{tabular}{cl}
\hline Alternativas & \multicolumn{1}{c}{ Descrição } \\
\hline 1 & Carvão \\
2 & Carvão + Serraria \\
3 & Carbono Total \\
4 & Carvão + Carbono Total \\
5 & Carvão + Serraria + Carbono Total \\
\hline
\end{tabular}

\begin{tabular}{|c|c|c|}
\hline Ano & Atividade & Custo (US $\$ /$ ha) \\
\hline 0 & Plantio & 342,41 \\
\hline $0, \ldots, 6$ & Custo Anual da Terra & 37,42 \\
\hline 1 & $1^{\text {a }}$ Manutenção & 95,40 \\
\hline 2 & $2^{\text {a }}$ Manutenção & 28,13 \\
\hline 3 & $3^{a}$ Manutenção & 24,48 \\
\hline 4 & 4a Manutenção & 24,48 \\
\hline 5 & $5^{\mathrm{a}}$ Manutenção & 24,48 \\
\hline 6 & $6^{a}$ Manutenção & 24,48 \\
\hline \multicolumn{2}{|c|}{ Total } & 825,79 \\
\hline
\end{tabular}

Quadro 3 - Custos operacionais anuais Table 3 - Annual operational costs

Fonte: Empresas do setor.

Quadro 4 - Preços da madeira em pé e da tonelada de carbono (C)

Table 4 - Prices for stand timber and carbon

\begin{tabular}{lrc}
\hline \multicolumn{1}{c}{ Item } & \multicolumn{2}{c}{ Preço } \\
\cline { 2 - 3 } & $\left(\mathrm{US} \$ / \mathrm{m}^{3}\right)$ & $(\mathrm{US} \$ / \text { ton })^{*}$ \\
\hline Madeira para Carvão & 7,17 & \\
Madeira para Serraria & 17,05 & 10,00 \\
Créditos de Carbono & & 100 \\
\hline
\end{tabular}

* tonelada de carbono $(\mathrm{C})$.

Para efeito deste estudo, consideraram-se não haver restrições de demanda no mercado para os diferentes produtos avaliados e que toda a quantidade de carbono estocada pudesse ser convertida em créditos de carbono, ou seja, que a linha de base do projeto fosse o solo, sem carbono estocado sobre ele. A validade ou não dos créditos de carbono não foi considerada no estudo, pois o objetivo do presente estudo foi avaliar o potencial de armazenamento de carbono pelas florestas para possíveis negociações com créditos de carbono.

Os critérios quantitativos considerados para análise foram: Valor Presente Líquido (VPL), Taxa Interna de Retorno (TIR) e Valor Esperado da Terra (VET), que consideram o valor do capital no tempo (SILVA et al., 2002). A taxa de juros comumente empregada para a utilização econômica de atividades florestais tem variado de 6 a $12 \%$ ao ano (LIMA JUNIOR, 1995). A taxa de desconto considerada neste estudo foi de $10 \%$ ao ano.

Como complemento, foram feitas análises de sensibilidade, identificando pontos de nivelamento entre os diferentes usos, pela variação dos custos, da taxa de juros e dos preços em amplitude de $\pm 20 \%$. 


\section{RESULTADOS E DISCUSSÃO}

De posse dos dados de dap e altura total $(H t)$, obtidos no inventário florestal, ajustou-se a seguinte equação hipsométrica:

$$
\operatorname{LnHt}=3,684694-8,689422 .\left(\frac{1}{d a p}\right) ; \quad \mathrm{R}^{2}=61 \%
$$$$
\mathrm{CV}=17,89 \%
$$

Pela distribuição dos resíduos porcentuais, na Figura 1, verifica-se que eles estão distribuídos uniformemente, não apresentando tendência de heterocedasticidade.

No Quadro 5, apresentam as estimativas dos parâmetros e as respectivas medidas de precisão, obtidas para o volume com casca.

Pela análise gráfica dos resíduos (Figura 2), observou-se uma leve tendência de superestimação dos volumes com casca e sem casca de árvores de maiores diâmetros (dap $>20 \mathrm{~cm})$.

Os volumes totalizados por parcela, considerandose os diferentes diâmetros de utilização da madeira $(d)$, bem como o erro de amostragem para o volume total de madeira, do inventário florestal (E\%), são apresentados no Quadro 6.

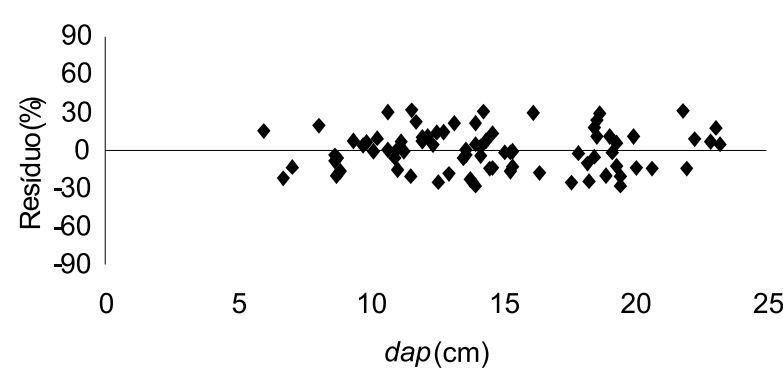

Figura1 - Distribuição dos resíduos porcentuais para a equação hipsométrica.

Figure 1 -Distribution of the percentual residues for the hypsometric equation.

Quadro 5 - Estimativas dos parâmetros do modelo de Kozak et al. (1969) e suas medidas de precisão

Table 5 - Estimates of the parameters for the Kozak et al. (1969) model and their precision measures

\begin{tabular}{lccccc}
\hline Volume & $\hat{\beta}_{0}$ & $\hat{\beta}_{1}$ & $\hat{\beta}_{2}$ & $\mathrm{CV}(\%)$ & $\mathrm{R}^{2}(\%)$ \\
\hline Com casca & 1,1314 & $-1,8368$ & 0,7325 & 16,57 & 93,7 \\
\hline
\end{tabular}

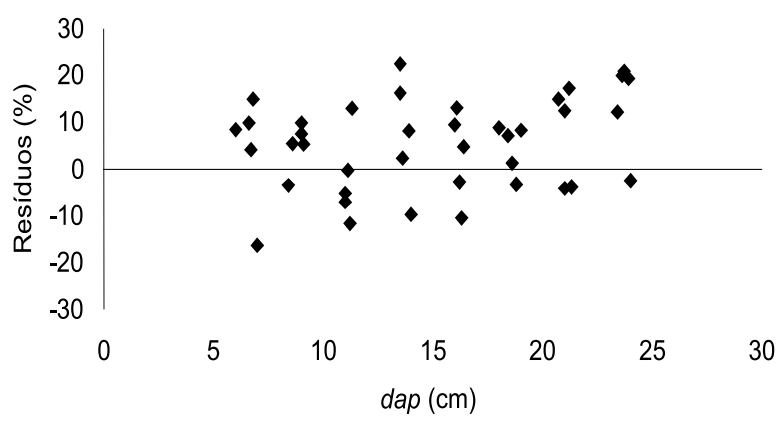

Figura 2 - Distribuição dos resíduos porcentuais do modelo de Kozak et al. (1969).

Figure 2 -Distribution of the percentual residues for the Kozak et al. (1969) model.

Quadro 6 - Volumes por parcela, estimativas médias e erro de amostragem

Table 6 - Volumes per plot, average estimates and sampling error

\begin{tabular}{|c|c|c|}
\hline \multirow[t]{2}{*}{ Parcela } & \multicolumn{2}{|c|}{ Volume $\left(\mathrm{m}^{3}\right)$} \\
\hline & Carvão & Serraria \\
\hline 1 & 5,16 & 0,71 \\
\hline 2 & 8,32 & 2,34 \\
\hline 3 & 6,55 & 1,26 \\
\hline 4 & 10,63 & 4,73 \\
\hline 5 & 6,44 & 1,94 \\
\hline 6 & 7,05 & 2,63 \\
\hline 7 & 12,07 & 7,39 \\
\hline 8 & 10,70 & 5,07 \\
\hline$\overline{\text { Total }}$ & $6 \overline{6,9} \overline{2}$ & 26,06 \\
\hline Média*/parcela & 8,16 & 3,06 \\
\hline $\mathrm{m}^{3} / \mathrm{ha}$ & 204,09 & 76,49 \\
\hline \multicolumn{2}{|c|}{$\mathrm{E}(\%)$} & 16,94 \\
\hline
\end{tabular}

* Média ponderada pela área dos estratos $(\mathrm{E} 1=4,0$ ha; $\mathrm{E} 2=1,0 \mathrm{ha})$.

Com as estimativas mostradas no Quadro 6, obtevese a estimativa de volume por hectare para as diferentes alternativas de uso da madeira (Quadro 7).

Considerando os dois usos para a madeira (carvão e serraria), do total de $204,09 \mathrm{~m}^{3} / \mathrm{ha}, 62,52 \%$ seriam destinados à produção de carvão e $37,48 \%$ à produção de madeira serrada.

Levando-se em conta os preços médios do metro cúbico da madeira em pé para a produção de carvão e serraria iguais a US\$ 7,17 e U\$ 17,05, respectivamente, e os volumes médios por hectare para os diferentes usos, ter-se-iam as receitas, apresentadas no Quadro 8.

R. Árvore, Viçosa-MG, v.30, n.3, p.411-420, 2006 
Quadro 7 - Estimativas médias dos volumes por hectare de diferentes alternativas de uso da madeira

Table 7 -Average estimates of the volume per hectare for the various alternatives of wood use

\begin{tabular}{ccc}
\hline Alternativa & Descrição & Volume $\left(\mathrm{m}^{3} / \mathrm{ha}\right)$ \\
\hline 1 & Carvão & 204,09 \\
2 & Carvão + Serraria & $127,60+76,49$ \\
\hline
\end{tabular}

Quadro 8-Receitas por hectare para as diferentes alternativas de uso da madeira

Table 8 -Incomes per hectare for the various alternatives of wood use

\begin{tabular}{ccc}
\hline Alternativa & Descrição & Receita (US\$/ha) \\
\hline 1 & Carvão & $1.463,32$ \\
2 & Carvão + Serraria & $2.219,04$ \\
\hline
\end{tabular}

Através do uso das equações de carbono e das unidades de amostra (parcelas) distribuídas na área de estudo, obtiveram-se as seguintes estimativas médias de carbono estocado por hectare para o fuste (sem casca), casca, galhos e folhas, que são apresentados na Figura 3.

O fuste sem casca é o componente da parte aérea com maior porcentual de contribuição $(81,84 \%)$, seguido por casca $(8,05 \%)$, galhos $(7,74 \%)$ e folhas $(2,57 \%)$. Dessa forma, verifica-se, na Figura 3, que o povoamento de eucalipto estudado possui, em média, 47,7 toneladas de carbono por hectare estocado na parte aérea das árvores.

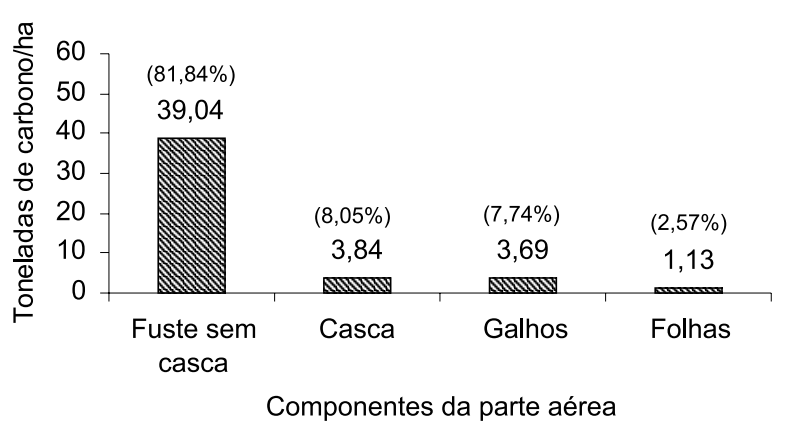

Figura 3 - Estimativas médias de carbono estocado por hectare nas folhas, galhos, fuste sem casca e com casca, em um plantio de Eucalyptus grandis, com 6 anos de idade, no Município de Viçosa, e os respectivos porcentuais de contribuição.

Figure 3-Average estimates of the stocked carbon per hectare in leaves, branches, stem outside bark and bark in a 6-year-old plantation of Eucalyptus grandis, located in Viçosa, Minas Gerais State, Brazil and respective percentages of contribution.

R. Árvore, Viçosa-MG, v.30, n.3, p.411-420, 2006
Como essa estimativa da parte aérea representa, em média, 67,06\% do carbono estocado na floresta nessa idade, segundo Paixão (2004), o carbono total será igual a 71,13 toneladas por hectare, dos quais 14,71 toneladas $(20,68 \%$ do carbono total) estão estocadas nas raízes e 8,72 toneladas (12,26\% do carbono total), na manta orgânica (Figura 4).

Considerando que a floresta de eucalipto possui 6 anos de idade, isso representa um incremento médio anual de 11,85 toneladas de carbono por hectare, por ano até essa idade.

Levando-se em consideração o preço de U\$ 10,00 por tonelada de carbono estocado e a estimativa do total de carbono estocado por hectare (71,13 toneladas), ter-se-ia uma receita de US\$ 711,30 por hectare.

A análise do Quadro 9 mostra que os projetos 1 (carvão), 2 (carvão e serraria), 4 (carvão e carbono total) e 5 (carvão, serraria e carbono total) são considerados viáveis, pois possuem VPLs positivos. O projeto 5 é considerado o melhor, por apresentar o maior VPL e VET, ou seja, mostra o maior retorno econômico, comparado ao dos demais. Isso se deve, obviamente, ao maior valor agregado pela diversificação da produção (carvão e serraria) e à venda de créditos de carbono.

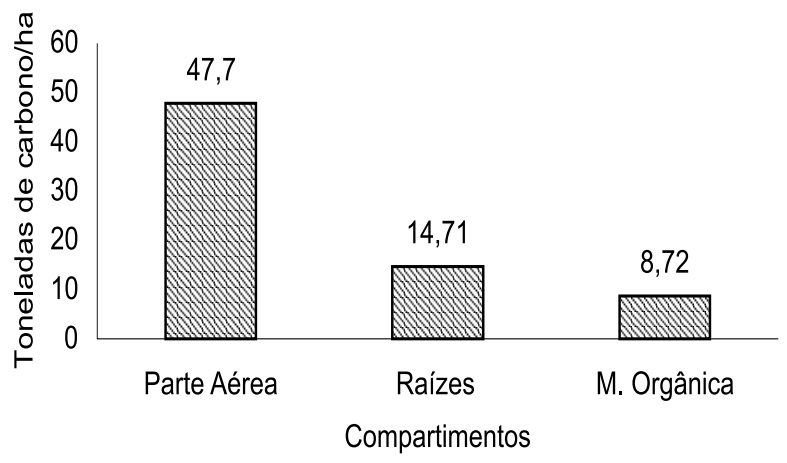

Figura 4 - Estimativas do carbono estocado por hectare na parte aérea das árvores, nas raízes e manta orgânica em um plantio de Eucalyptus grandis, com 6 anos de idade, no Município de Viçosa.

Figure 4-Estimates of stocked carbon per hectare in the aerial parts of the trees, in the roots and organic litter in a 6-year-old plantation of Eucalyptus grandis, located in Viçosa, Minas Gerais State, Brazil. 
Quadro 9 - Estimativas do valor presente líquido (VPL) e valor esperado da terra (VET), considerando uma taxa de desconto igual a $10,00 \%$ a.a. e taxa interna de retorno (TIR)

Table 9 - Estimates of net present value (VPL) and expected value of land (VET), considering a interest rate equal to $10.00 \%$ per year, and internal rate of return (TIR)

\begin{tabular}{|c|c|c|c|c|}
\hline Projeto & Descrição & $\begin{array}{c}\text { VPL } \\
\text { (US\$/ha) }\end{array}$ & $\begin{array}{l}\text { TIR } \\
(\%)\end{array}$ & $\begin{array}{c}\text { VET } \\
\text { (US\$/ha) }\end{array}$ \\
\hline 1 & Carvão & 109,10 & 13,34 & 624,71 \\
\hline 2 & $\begin{array}{l}\text { Carvão }+ \\
\text { serraria }\end{array}$ & 535,68 & 23,37 & $1.604,18$ \\
\hline 3 & $\overline{\text { Carbono total }}$ & $-\overline{5,61}$ & 10,67 & 361,33 \\
\hline 4 & $\begin{array}{l}\text { Carvão + } \\
\text { carbono total }\end{array}$ & 820,40 & - & $\overline{2.257}, \overline{90}$ \\
\hline 5 & $\begin{array}{l}\text { Carvão + serraria } \\
+ \text { carbono total }\end{array}$ & $1.246, \overline{98}$ & - & $3.237,37$ \\
\hline
\end{tabular}

As TIRs (Taxa Interna de Retorno) foram calculadas apenas para os projetos 1 e 2, uma vez que para os demais as receitas auferidas no ano zero (0) superam os custos descontados nesse mesmo ano, de tal forma que não existe uma taxa que anule o VPL. Com base nesse critério, os projetos 1 e 2 apresentaram TIRs maiores do que a taxa de desconto, sendo, portanto, considerados viáveis.

Embora o preço da tonelada de carbono por hectare seja menor do que o metro cúbico de madeira para serraria, verifica-se, no Quadro 9, que o VPL do projeto 4 é maior que o do projeto 2. Esse aumento no VPL se deve ao fato de as receitas auferidas pela venda de créditos de carbono se efetivarem no início do projeto (ano 0), enquanto a receita auferida pela venda da madeira para a serraria ocorre no final da rotação (sexto ano).

O Quadro 9 mostra, ainda, que o VPL do projeto 3 é negativo, indicando que o reflorestamento destinado somente à venda de créditos de carbono no mercado, tendo em vista os custos, as receitas e o horizonte de planejamento considerado, é inviável economicamente, ou seja, os custos do empreendimento superam receitas advindas somente da venda dos créditos de carbono. No entanto, tendo em vista as estimativas obtidas para os critérios econômicos (VPL e TIR), verifica-se que um pequeno aumento no preço da tonelada de carbono ou uma pequena redução nos custos de produção tornam o projeto 3 economicamente viável.
O VET representa o preço máximo a ser pago pela terra nua. Os projetos 1, 2, 4 e 5 apresentaram VETs superiores ao preço da terra nua (US\$ 374,20), sendo, portanto, viáveis. Para o projeto 3, obteve-se um VET inferior ao preço da terra nua, sendo, portanto, considerado inviável economicamente. A possibilidade de aquisição de terras mais caras teria reflexos diretos sobre a produção, os custos de implantação e o transporte. A aquisição de terras mais férteis reduziria os custos de correção de solos, além de elas proporcionarem maior produção e, consequientemente, empreendimentos mais rentáveis. Da mesma forma, a possibilidade de aquisição de terras mais próximas de centros consumidores, ferrovias ou portos, para escoamento da produção, reduziria o custo com transporte e aumentaria também a rentabilidade do empreendimento florestal.

Vale ressaltar que o povoamento em estudo foi implantado com baixa tecnologia e em pequena escala. A adoção de tecnologias mais avançadas e em maior escala pode levar à redução do custo médio de produção $\left(\mathrm{US} \$ / \mathrm{m}^{3}\right.$ ) e aumentar a produtividade e, conseqüentemente, a taxa e o acúmulo final de $\mathrm{CO}_{2}$ no povoamento.

A análise de sensibilidade, considerando-se o critério econômico VPL, de todos os projetos (1 a 5), foi realizada submetendo os custos, as receitas e as taxas de juros a variações de seus valores em $\pm 20 \%$ (Quadro 10).

Analisando o Quadro 10 e a Figura 5, verificouse, no projeto 1 (carvão), que o VPL foi sensível às variações porcentuais no custo total, na receita total e na taxa de juros. Mantendo-se constante o custo de produção, o horizonte de planejamento de 6 anos e a taxa de desconto de $10 \%$ a.a., o projeto 1 seria viável economicamente se o preço da madeira para a produção de carvão fosse superior a US\$ 6,21 por $\mathrm{m}^{3}$ (redução de $13,4 \%$ em relação ao valor inicial de US $\$ 7,17$ por $\mathrm{m}^{3}$ ). Sustentando-se o preço da madeira para produção de carvão em US\$ 7,17 (preço da madeira inicialmente adotado na análise econômica), o horizonte de planejamento de 6 anos e a taxa de desconto de $10 \%$ a.a., o custo máximo de produção que viabiliza o projeto 1 seria de US\$ 952,14 por hectare (aumento de 13,27\% em relação ao custo de produção inicialmente adotado, de US $\$ 825,79$ por hectare).

R. Árvore, Viçosa-MG, v.30, n.3, p.411-420, 2006 
Quadro 10 - Análise de sensibilidade do valor presente líquido (VPL)

Table 10 -Sensitivity analysis for the net present value (VPL)

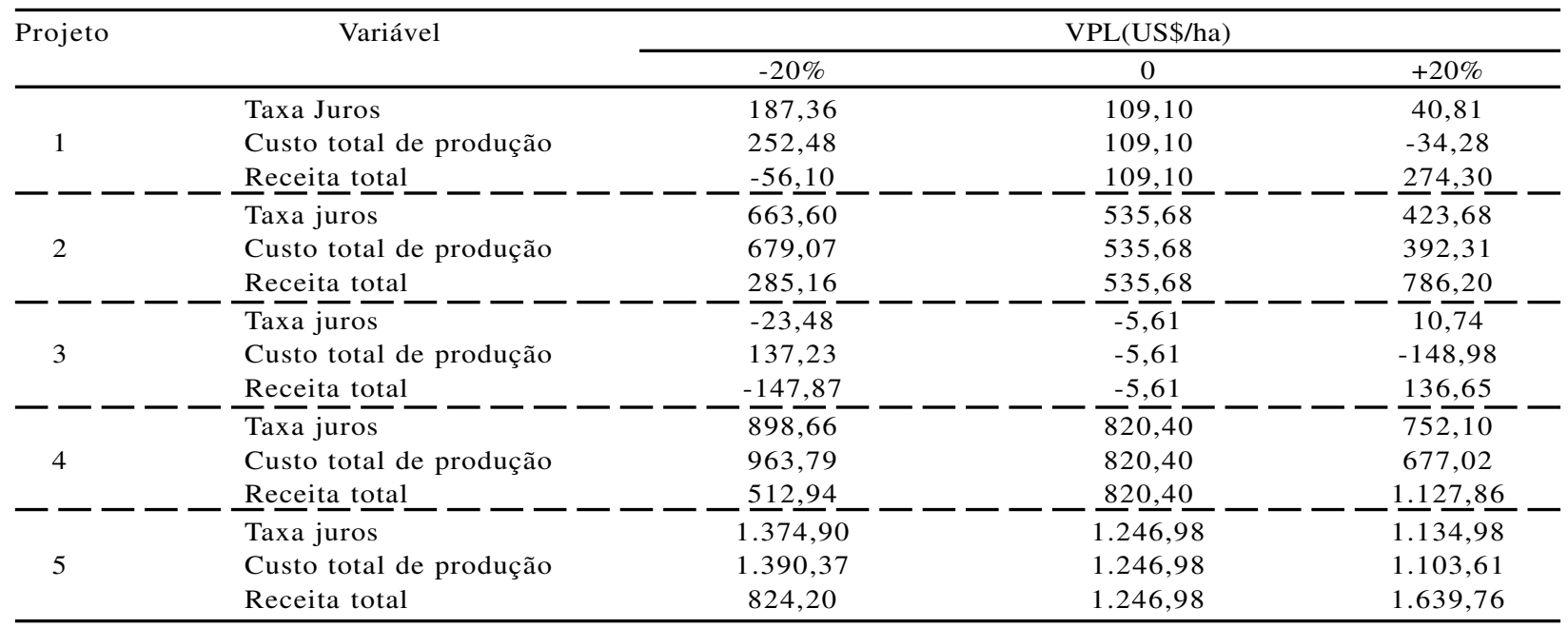

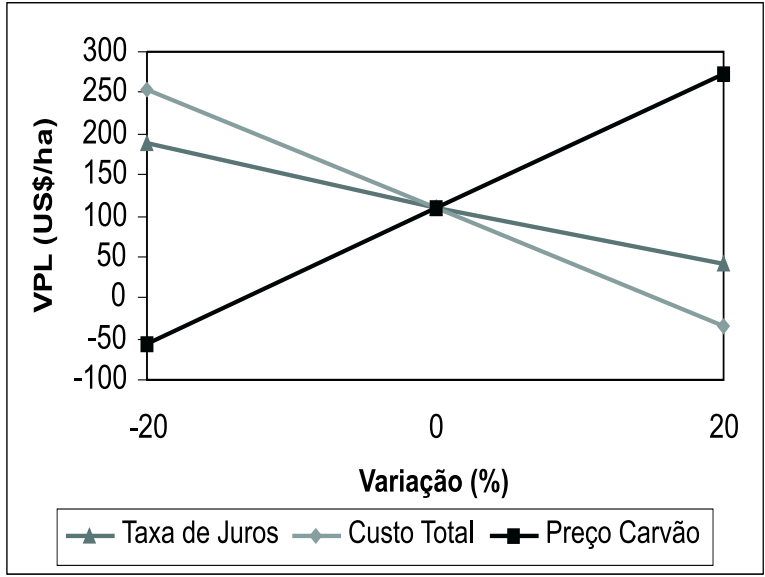

Figura 5 - Valores de VPL para o projeto 1, considerandose as variações porcentuais na taxa de juros, no custo total e no preço da madeira para carvão.

Figure 5-Net present values (VPL) for the project 1, considering the percentage variations in the interest rate, in the total cost and in the price of the wood for coal.

Reduções no custo total de produção viabilizam economicamente o projeto 3, da mesma forma que o aumento na receita total (Quadro 10 e Figura 6). Assim, mantendo-se constante o custo de produção, o horizonte de planejamento de 6 anos e a taxa de desconto de $10 \%$ a.a., o projeto 3 , ou seja, plantio de povoamentos visando ao atendimento exclusivo do MDL (sem agregar valor à madeira), seria economicamente viável se os créditos de carbono fossem vendidos no mínimo por
US\$10,07 a tonelada. Mantendo-se o preço da tonelada de carbono igual a US\$10,00 (preço da tonelada de carbono inicialmente adotado na análise econômica), o horizonte de planejamento igual a 6 anos e a taxa de desconto de $10 \%$ a.a., o custo máximo de produção que viabiliza o projeto 3 seria de US $\$ 819,35$ por hectare (redução de $0,78 \%$ em relação ao custo de produção inicialmente adotado, de US $\$ 825,79$ por hectare).

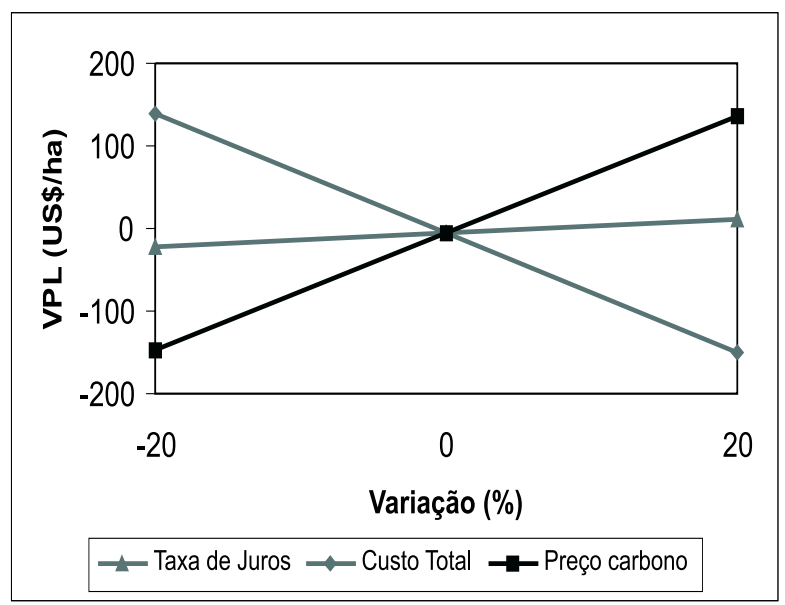

Figura 6 - Valores de VPL para o projeto 3, considerandose as variações porcentuais na taxa de juros, no custo total e no preço da tonelada de carbono.

Figure 6-Net present values (VPL) for the project 3 , considering the percentage variations in the interest rate, in the total cost and in the price of the ton of carbon. 
A análise do Quadro 10 mostra ainda que variações porcentuais na taxa de juros geram resultados com padrões diferentes dos demais projetos, porque as receitas com a venda de créditos de carbono auferidas no ano zero não sofrem desconto para cálculo do VPL. Já a descapitalização dos custos totais à taxa menor (8\%) gera valores presentes maiores no ano zero, justificando, assim, o VPL ainda mais negativo.

Variações porcentuais na taxa de juros, no custo total de produção e na receita total não inviabilizam a execução dos projetos 2, 4 e 5; em todas as variações sofridas, o resultado final ainda é superior a qualquer resultado obtido no projeto 1 , o que se deve à diversificação da produção, tornando o empreendimento mais seguro e menos sensível a variações de preços do mercado, bem como nos custos de produção.

\section{CONCLUSÕES}

Após as análises, verificou-se que:

- O fuste é o componente da árvore que mais contribui, em média, para o total de carbono da parte aérea $(81,84 \%)$, seguido por casca $(8,05 \%)$, galhos $(7,74 \%)$ e folhas $(2,57 \%)$.

- No povoamento estudado, 47,7 toneladas de carbono por hectare estão estocadas na parte aérea das árvores, 14,71 nas raízes e 8,72 na manta orgânica, totalizando 71,13 toneladas de carbono total por hectare, aos 6 anos de idade.

- Levando-se em conta a estrutura de custos e as receitas adotadas neste estudo, a produção de madeira somente para a venda de créditos de carbono, sem considerar o seu uso final, é economicamente viável, segundo critérios quantitativos de avaliação do projeto (VPL, TIR e VET), se a tonelada de carbono for comercializada a preços maiores que U\$ 10,07.

- A inclusão da venda de créditos de carbono torna o empreendimento ainda mais atrativo economicamente, sobretudo porque a receita auferida no início do projeto reflete positivamente nos critérios de avaliação econômica.

\section{REFERÊNCIAS BIBLIOGRÁFICAS}

CALDEIRA, M.V.W. et al. Carbono orgânico em solos florestais. In: SANGUETA, C. R. et al. (Ed.). As florestas e o carbono. Curitiba: 2002. p. 191-214.
CEPEA, 2003. Disponível em:

$<$ www.cepea.esalq.usp.br/economiaflorestal/ informativo mensal.htm>. Visitado em: set de 2003.

KOZAK, A.; MUNRO, D.D.; SMITH, J.H.G. Taper functions and their application in forest

inventory. The Forest Chronicle, v. 45, n. 4, p. 278-283, 1969.

LEITE, H.G. Conversão de tronco em multiprodutos de madeira, utilizando programação dinâmica. 1994. 230f. Tese (Doutorado em Ciência Florestal) - Universidade Federal de Viçosa, Viçosa, 1994.

LIMA JUNIOR, V. B. Determinação da taxa de desconto para uso na avaliação de projetos de investimentos florestais. 1995. 90f. Dissertação (Mestrado em Ciência Florestal) - Universidade Federal de Viçosa, Viçosa, 1995.

PAIXÃO, F. A. Quantificação do Estoque de Carbono em Floresta Plantada de Eucalipto e Avaliação Econômica de Diferentes Alternativas de Manejo. 2004. 76f. Dissertação (Mestrado em Ciência Florestal) - Universidade Federal de Viçosa, Viçosa, 2004.

REZENDE, A.V. O estoque de carbono no cerrado: um estudo de caso. In: SANGUETA, C. R. et al. (Ed.). As florestas e o carbono. Curitiba: 2002. p. 175-191.

ROCHA, M. T. O aquecimento global e os instrumentos de mercado para a solução do problema. In: SANGUETA, C. R. et al. (Ed.). As florestas e carbono. Curitiba: 2002. p. 1-34.

SCHUMACHER, M.V. et al. Estoque de carbono em florestas plantadas de Pinus taeda L. e Acácia mearnsii De Wild. Plantadas no estado do Rio Grande do Sul - Brasil. In: SANGUETA, C. R. et al. (Ed.). As florestas e o carbono. Curitiba: 2002. p. 141-152.

SILVA, M.L.; JACOVINE, L.A.G.; VALVERDE, S.R. Economia Florestal. Viçosa, MG: UFV, 2002. 178p.

R. Árvore, Viçosa-MG, v.30, n.3, p.411-420, 2006 
SOARES, C.P.B.; PAULA NETO, F. Determinação do tamanho da amostra em um inventário volumétrico e de biomassa de troncos. Revista Ceres, v. 44, n. 252, p. 142-151, 1997.

SOARES, C.P.B.; OLIVEIRA, M. L.R. Equações para estimar a quantidade de carbono presente na parte aérea de árvores de eucalipto em

Viçosa, Minas Gerais. Revista Árvore, v. 26, n. 5, p. 533-539. 2002.
WALTZLAWICK, L.F. et al. Fixação de carbono em floresta ombrófila mista em diferentes estágios de regeneração. In: SANGUETA, C. R. et al. (Ed.). As florestas e o carbono. Curitiba: 2002. p. 153-174.

YU, C. M. Caracterização e tipologia do projetos de seqüestro de carbono no Brasil. In:

SANQUETTA, C. R. et al. (Ed.). As florestas e o carbono. Curitiba: 2002. p. 59-87. 